The following text is provided by DuEPublico, the central repository of the University DuisburgEssen.

This version of the e-publication released on DuEPublico may differ from a potential published print or online version.

Engenhorst, Markus; Fecher, Jonas; Notthoff, Christian; Schierning, Gabi; Schmechel, Roland; Rosiwal, Stefan M.:

\title{
Thermoelectric transport properties of boron-doped nanocrystalline diamond foils
}

DOI: http://dx.doi.org/10.1016/j.carbon.2014.10.002

URN: urn:nbn:de:hbz:464-20170112-164836-4

Link: http://duepublico.uni-duisburg-essen.de/servlets/DocumentServlet?id=42873

License:

This work may be used under a Creative Commons Namensnennung - Nicht kommerziell - Keine Bearbeitungen 4.0 International license.

Legal notice:

(C) 2014. This manuscript version is the accepted author manuscript. Proofs by the authors have been adopted into this version. This version underwent no copy-editing and formatting by the editors, according to Elsevier's Green Open Access. It was published in December 2016, after the journal Carbon's embargo period of 24 months.

The published journal article can be found here: http://dx.doi.org/10.1016/j.carbon.2014.10.002

Source: Carbon 81 (2015), pp. 650-662 
(C) 2014. This manuscript version is made available under the CC-BY-NC-ND 4.0 license

This manuscript version is the accepted author manuscript. Proofs by the authors have been adopted into this version. This version underwent no copy-editing and formatting by the editors, according to Elsevier's Green Open Access. It was published in December 2016, after the journal Carbon's embargo period of 24 months.

The published journal article can be found here: http://dx.doi.org/10.1016/j.carbon.2014.10.002 cite as: Engenhorst, M.; Fecher, J.; Notthoff, C.; Schierning, G.; Schmechel, R.; Rosiwal, S.M.: "Thermoelectric Transport Properties of Boron-doped Nanocrystalline Diamond Foils". Carbon 81 (2015), pp. $650-662$.

\title{
Thermoelectric Transport Properties of Boron-doped Nanocrystalline Diamond Foils
}

\section{Markus Engenhorst ${ }^{a, *}$, Jonas Fecher ${ }^{b}$, Christian Notthoff ${ }^{a}$, Gabi Schierning ${ }^{a}$, Roland Schmechel ${ }^{a}$, Stefan M. Rosiwal}

${ }^{\text {a }}$ Faculty of Engineering and Center for Nanointegration Duisburg-Essen (CENIDE), University of Duisburg-Essen

Bismarckstraße 81, 47057 Duisburg, Germany

${ }^{\mathrm{b}}$ Chair of Metals Science and Technology (WTM), University of Erlangen-Nuernberg

Martensstraße 5, 91058 Erlangen, Germany

* Corresponding author: E-mail address: markus.engenhorst@uni-due.de

\begin{abstract}
Natural diamond is known for its outstanding thermal conductivity and electrical insulation. However, synthetic production allows for doping and tailoring microstructural and transport properties. Despite some motivation in the literature and the ongoing search for abundant and nontoxic thermoelectric materials, the first experimental study on a set of eight substrate-free borondoped nanocrystalline diamond foils is presented herein. All transport coefficients were determined in the same direction within the same foils over a broad temperature range up to $900{ }^{\circ} \mathrm{C}$. It is found that nanostructuring reduces the thermal conductivity by two orders of magnitude, but the mobility decreases significantly to around $1 \mathrm{~cm}^{2} \mathrm{~V}^{-1} \mathrm{~s}^{-1}$, too. Although degenerate transport can be concluded from the temperature dependence of the Seebeck coefficient, charge carriers notably scatter at grain boundaries where $\mathrm{sp}^{2}$-carbon modifications and amorphous boron-rich phases form during synthesis. A detailed analysis of doping efficiency yields an acceptor fraction of only 8 to 18 at $\%$, meaning that during synthesis excess boron thermodynamically prefers electrically inactive sites. Decent power factors above $10^{-4} \mathrm{~W} \mathrm{~m}^{-1} \mathrm{~K}^{-2}$ at $900^{\circ} \mathrm{C}$ are found despite the low mobility, and a Jonker-type analysis grants a deeper insight into this issue. Together with the high thermal conductivity, the thermoelectric figure of merit $z T$ does not exceed 0.01 at $900{ }^{\circ} \mathrm{C}$.
\end{abstract}

\section{Introduction}

Nature uses harsh conditions to create diamond, i.e. high temperature and high pressure. This process results in a material with outstanding properties such as the highest thermal conductivity, 
one of the widest band gaps, highest hardness, smallest molar volume, strongest bonds, lowest diffusion coefficients and therefore excellent stability at high temperature and against chemical or mechanical wear.

No matter how desirable the latter properties may make diamond for a broad variety of applications, its high thermal conductivity and electrical resistivity seem to disallow its application in the field of thermoelectric power generation. But then, in turn, synthetic processes like chemical vapor deposition (CVD) provide parameters to tailor the material's chemistry, microstructure and overall transport properties. Many established thermoelectric materials $\left(\mathrm{Bi}_{2} \mathrm{Te}_{3}, \mathrm{PbTe}, \mathrm{SiGe}\right)$ are toxic and not abundantly available as required for their use in industrial mass products. The production of CVD-diamond does not depend on rare or toxic raw materials, as only hydrogen, methane and electric energy are needed. Cheap dopant precursors with low toxicity are readily available and only needed in small amounts. The production volume is fully scalable by adjusting the number and size of coating machines.

In thermoelectrics, the general necessity of tailoring the Seebeck coefficient $\alpha$, the electrical conductivity $\sigma$ and the thermal conductivity $\kappa$ as independently as possible can easily be seen from their relation with the dimensionless figure of merit $z T$ given in Equation (1).

$$
z T=\frac{\alpha^{2} \cdot \sigma}{\kappa} \cdot T
$$

All transport properties in turn are functions of the absolute temperature $T$. The numerator $\alpha^{2} \sigma$ is commonly referred to as the power factor. An increase in the figure of merit can be achieved, e.g., via the optimization of the charge carrier concentration and the microstructure, where the latter has gained attention in the last two decades with the ascent of nanostructured and nanocomposite materials for enhancing the Seebeck coefficient and reducing the thermal conductivity.[1-4] In addition to the possibility of nanostructuring, some strong motivation to investigate the thermoelectric properties of CVD diamond can be found in the literature, which will be assessed in the following section. For a consistent experimental study, a set of eight foils was deposited with varying boron concentration in two different hot filament CVD (HFCVD) reactors. The chemical composition and the microstructure were characterized using glow discharge optical emission spectroscopy (GDOES), scanning electron microscopy (SEM) and X-ray diffraction (XRD). Thermoelectric transport coefficients were measured perpendicularly to the growth direction (in the plane of the foils) between room temperature and $900^{\circ} \mathrm{C}$. From these data, the charge carrier concentration, the mobility and the doping efficiency are calculated. A Jonker-type analysis reveals the influence of the mobility on the power factor. Since our study investigates all transport properties in the same direction within the same specimens, it is the first to assess the overall thermoelectric figure of merit. Besides this, the single transport coefficients and their temperature dependence could be of interest for researchers applying nanocrystalline diamond as a surface coating with outstanding mechanical properties.[5]

\section{Thermoelectric transport in CVD diamond}

In 1987, Revin measured a decent power factor of $10^{-5} \mathrm{~W} \mathrm{~m}^{-1} \mathrm{~K}^{-2}$ in single-crystalline, synthetic, nominally undoped $p$-type diamond and attributed this result to the very high carrier mobility, recognizing the potential application of diamond as a thermoelectric material.[6] Triggered by the aforementioned developments in nanotechnology and the discovery of ultrananocrystalline diamond (UNCD), Gruen suggested the investigation of UNCD and related carbon composites with regard to 
their thermoelectric properties.[7] Another stimulus comes from the high Debye temperature of diamond, raising the question whether the phonon drag effect could be used at temperatures well above room temperature. This effect was experimentally shown in high quality crystals with doping concentrations lower than $10^{17} \mathrm{~cm}^{-3} \cdot[8,9]$ A calculation for a nanocomposite of diamond and graphite predicted very large $z T$ values [10], whereas other sources find the application of the phonon drag effect unlikely due to the high charge carrier concentration needed for thermoelectrics.[11,12]

Most easily, doping of diamond is achieved with boron due to its negative formation energy and its size.[13] Boron forms a deep acceptor level at $0.37 \mathrm{eV}$ above the valence band edge, which decreases to about $0.1 \mathrm{eV}$ with increasing dopant concentration.[14,15] Astonishingly, only very few reports on Seebeck coefficients in boron-doped CVD-diamond can be found in the literature, and no reports show data below $250 \mathrm{~K}$ or above $350 \mathrm{~K}$.[7,16-18] A recent theoretical approach [19] calculates Seebeck coefficients from experimental Hall and resistivity data in a $p$-type CVD-singlecrystal.[20] Mainly older sources use the Seebeck effect in order to confirm $p$-type conduction.[14,21-23] The scarcity of experimental data may be explained with the high thermal conductivity of diamond leading to experimental difficulties as mentioned by Revin [6] and by Horiuchi et al.[18]

From the viewpoint of thermoelectrics, the reduction of thermal conductivity in diamond is a key aspect, demanding grain sizes well below the micrometer range. In the 1990s, much emphasis was laid on perfecting CVD films to increase their thermal conductivity for heat spreading applications.[24,25] The columnar microstructure in these films was found responsible for a large anisotropy and thickness dependence of the thermal conductivity: Thinner films with much smaller average grain size show much lower thermal conductivity, especially perpendicularly to the growth direction.[26] Such a columnar structure is not found in the case of UNCD due to its homogeneous growth within the thickness range reported.[27,28] The resulting thermal conductivity may be very low, e.g., $2 \mathrm{~W} \mathrm{~m}^{-1} \mathrm{~K}^{-1}$ [7], but the implications on other transport properties remain unclarified. Since the introduction of grain boundaries will affect the charge carrier transport, several effects and contributions should be mentioned. In and around the grain boundaries, carbon will largely adopt $\mathrm{sp}^{2}$-hybridized bonds, generating additional states in the band structure.[29] With decreasing grain size, e.g. UNCD of 3-5 nm synthesized in a plasma containing nitrogen, the $\mathrm{sp}^{2}$-content increases to up to $15 \mathrm{at} \%$.[30] This leads to the consideration of the grain boundaries as a matrix phase in a composite of amorphous carbon and trans-polyacetylene-like structures and to the assumption that, in this case, the matrix possibly contributes significantly to electrical conduction.[30] Despite this contribution, quite low mobilities around $1 \mathrm{~cm}^{2} \mathrm{~V}^{-1} \mathrm{~s}^{-1}$ are found in $\mathrm{UNCD}$ [31], opposing the potential idea that $\mathrm{sp}^{2}$-carbon grain boundaries may benefit charge carrier transport as compared to the transport within the grain: the hole mobility in single-crystalline diamond is well above $1000 \mathrm{~cm}^{2} \mathrm{~V}^{-1} \mathrm{~s}^{-1}$.[32] In the case of doping high-pressure, high-temperature diamond with boron, the dopant tends to accumulate in the grain boundaries, and it has been hypothesized that superconductivity arises from intergranular boron-rich material.[33] In particular, segregation of boron is expected when its amount exceeds $5 \times 10^{20} \mathrm{~cm}^{-3}$, the limit for substitution of carbon in the diamond lattice.[34] 


\section{Experimental}

\subsection{Manufacturing}

HFCVD technique is used to grow diamond on silicon templates. The atmosphere of the reactor chamber contains mainly hydrogen and 1 to 5 vol\% methane at a constant pressure between 2 mbar and 8 mbar. Carburized tungsten wires, which are resistively heated up to $2300{ }^{\circ} \mathrm{C}$, are used for the formation of hydrogen radicals, which react with methane to form methyl radicals. The methyl radicals are deposited on the surface of the silicon templates and form a diamond layer, since $\mathrm{sp}^{2}$ carbon is widely etched by the hydrogen radicals.

Prior to the HFCVD-process the silicon template is seeded with nanodiamond crystals $(4.2 \pm 0.5 \mathrm{~nm})$ in order to achieve a high seed density, resulting in a fast and homogeneous formation of the diamond layer at the beginning of the deposition. The higher the methane concentration in the gas phase and therefore the concentration of ethyne $\left(\mathrm{C}_{2} \mathrm{H}_{2}\right)$, the higher the rate of secondary nucleation, leading to smaller grains. This is the main parameter to tailor the grain size for the respective application. Besides etching $\mathrm{sp}^{2}$-carbon, the hydrogen radicals supply heat to sustain coating temperatures of $750-900{ }^{\circ} \mathrm{C}$ by heterogeneous recombination on the surface of the template.

The diamond foils were manufactured in two different industrial HFCVD diamond coating machines where three 4" silicon wafers (reactor A: Cemecon CC800/8) or nine 6" silicon wafers (reactor B: Cemecon CC800/9 Dia XL) were coated on both sides in every process. Gaseous trimethyl borate $\left(\mathrm{B}\left(\mathrm{OCH}_{3}\right)_{3}\right)$ was used as dopant precursor in both reactors. After $100-160 \mathrm{~h}$, foils with a thickness in the range between $20 \mu \mathrm{m}$ and $70 \mu \mathrm{m}$ were obtained from the HFCVD process. The foils A1 to A5 were deposited in reactor A at $8 \mathrm{mbar}$, at a volume fraction of methane of $3.6 \mathrm{vol} \%$ and at a volume fraction of trimethyl borate ranging from $0.01 \mathrm{vol} \%$ to $0.05 \mathrm{vol} \%$. In reactor $\mathrm{B}$, the fractions of precursor gases and the pressure were matched as specified in Table 1 in order to achieve different boron fractions in the foils while keeping the grain size small.

\subsection{Preparation}

After deposition, patterns matching the desired shapes for characterization were laser cut into the foils. The foils were subsequently removed from the substrates in a high power ultrasonic bath where they usually delaminate due to internal stress.[35,36] For thermal diffusivity determination, circular foils of 20 to $24 \mathrm{~mm}$ diameter were obtained and used without further preparation. For measurements of the Seebeck coefficient and the electrical conductivity, rectangular pieces of $9 \times 2 \mathrm{~mm}^{2}$ were prepared. As shown in Figure 1a), the foils were attached to rectangular alumina cuboids of $10 \times 3 \times 2 \mathrm{~mm}^{3}$ applying conductive silver lacquer along the shorter faces of the foils

Table 1. Manufacturing parameters for all foils and their respective thickness at the end of the deposition process.

\begin{tabular}{|c|c|c|c|c|c|c|}
\hline foil & reactor & $\begin{array}{r}\text { volume fraction } \\
\text { of borate } \\
\text { [vol\%] }\end{array}$ & $\begin{array}{r}\text { volume fraction } \\
\text { of methane } \\
{[\mathrm{vol} \%]}\end{array}$ & $\begin{array}{r}\text { pressure } \\
\text { [mbar] }\end{array}$ & $\begin{array}{r}\text { thickness } \\
{[\mu \mathrm{m}]} \\
\end{array}$ & symbol \\
\hline $\mathrm{A} 1$ & \multirow{5}{*}{$\begin{array}{l}\text { A: Cemecon } \\
\text { CC800/8 }\end{array}$} & 0.01 & 3.6 & 8 & 21 & \\
\hline $\mathrm{A} 2$ & & 0.02 & 3.6 & 8 & 21 & \\
\hline A3 & & 0.03 & 3.6 & 8 & 23 & $\square$ \\
\hline A4 & & 0.04 & 3.6 & 8 & 23 & च \\
\hline A5 & & 0.05 & 3.6 & 8 & 23 & ] \\
\hline B1 & \multirow{3}{*}{$\begin{array}{l}\text { B: Cemecon } \\
\text { CC800/9-Dia XL }\end{array}$} & 0.02 & 1.8 & 2 & 57 & $\mathrm{O}$ \\
\hline B2 & & 0.15 & 5.0 & 6 & 59 & $\oplus$ \\
\hline B3 & & 0.15 & 4.4 & 6 & 72 & $\not$ \\
\hline
\end{tabular}


which were subsequently contacted with the silver lacquered end faces $\left(3 \times 2 \mathrm{~mm}^{2}\right)$ of the cuboids on either side. Furthermore, the end faces were covered with graphite foils in order to prevent diffusion of silver into the electrodes of the measurement equipment. Alumina serves as a mechanical support and as a heat spreader in order to minimize the temperature difference between the location of potential probing at the foil's surface and the respective thermocouple bead.[37] The alumina substrate can be regarded as electrically inactive since it is an insulator.

\subsection{Characterization}

The overall fraction of boron incorporated into the foils $X_{\mathrm{B} \text {,foil }}$ was measured using GDOES in a GD Profiler (Horiba Jobin Yvon $\mathrm{GmbH}$ ) where an Ar plasma dry etches the foils within a circular area with a diameter of about $5 \mathrm{~mm}$. The boron fraction is determined from the spectrum of the optical emission in the plasma and averaged over an etching depth of several micrometers. Therefore, the method is not sensitive to the original chemical surrounding of boron, but determines its total fraction in the foil no matter whether it had previously been located within a grain or within a grain boundary.

The microstructure was investigated by SEM in a Jeol JSM-7500F and by XRD performed in a $P$ ANalytical X'Pert PRO powder diffractometer ( $\theta-\theta$-geometry) equipped with a Ni-filtered $\mathrm{Cu}-\mathrm{K}_{\alpha}$ $(1.5418 \AA) X$-ray source and an $X^{\prime}$ Celerator detector. The foils were mounted on a silicon zerobackground holder and rotated during the measurement. MAUD [38] and a heavily modified version of MStruct [39] were used for Rietveld refinement of the X-ray data in the range $37^{\circ}<2 \theta<100^{\circ}$. A reasonable Rietveld refinement was achieved assuming four diamond phases, with the lattice constant, crystallite size and the relative peak intensities as free parameters.

Because of the anisotropic microstructure of the foils and its thickness dependence, special care was taken concerning the microstructural characterization and the transport measurements. All transport coefficients were determined in the direction perpendicular to the growth direction, i.e. in-plane. Top-view micrographs were quantitatively evaluated in order to obtain a measure of the grain diameter. The projected area of apparent grains was measured and their equivalent circular diameter was calculated. Differences in area were not weighted so that the area based average diameter $d$ was obtained. Since the top-view only considers the upmost surface, grains of decreasing size in buried

a)

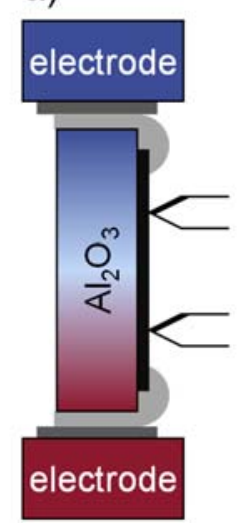

b)
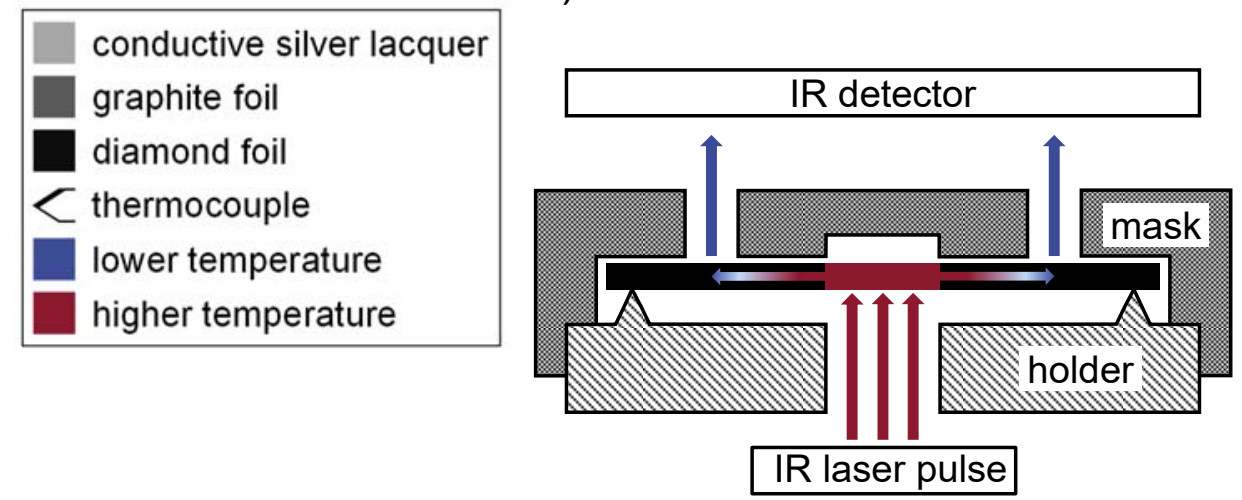

Figure 1. a) Diamond foil in its assembly for in-plane electrical conductivity and Seebeck coefficient measurement. The assembly is sandwiched between two electrodes and contacted by two spring-loaded thermocouples. A heater below the lower electrode can create a static temperature gradient along the assembly. b) In-plane thermal diffusivity is determined in a laser flash method: a short infrared (IR) pulse heats the center of the foil, the heat spreads outwards and the time-dependency of the temperature rise is observed through an annular window in the mask. 
layers and grains partly covered by other grains could not correctly be accounted for. The largest deviation between the average in-plane diameter (as determined from the top-view) and a more realistic diameter (averaged over the whole thickness) will occur for thick, microcrystalline foils. Still, the top-view average diameter might give a good impression of the structural influence on phonon and hole transport in the two dimensional top layer.

The Seebeck coefficient and the electrical conductivity were measured in-plane in a ZEM-3 (UlvacRiko, Inc.) in He at 100 mbar between $40{ }^{\circ} \mathrm{C}$ and $890{ }^{\circ} \mathrm{C}$. As shown in Figure 1a), the assembly is sandwiched between two planar electrodes that can drive a current through the foil. The foil is contacted by two spring-loaded thermocouples that also serve as voltage probes. Thus, the electrical conductivity measurement exploits the advantages of four-terminal sensing. Multiple static temperature gradients are created by a resistive heater below the lower electrode in order to determine the Seebeck coefficient from the thermovoltage and the temperature difference between the thermocouples, known as the static DC method.

The in-plane thermal diffusivity $\lambda$ was determined in an LFA 457 Microflash (Netzsch-Gerätebau $\mathrm{GmbH}$ ) in a nitrogen flow of $75 \mathrm{sccm}$ at atmospheric pressure between $30^{\circ} \mathrm{C}$ and $700{ }^{\circ} \mathrm{C}$. A schematic of the in-plane setup is provided in Figure 1b). The incident laser pulse is reduced to a diameter of $5 \mathrm{~mm}$, heating up the center of the circular foil from where the heat spreads in rotational symmetry. The time dependency of the temperature rise is observed through an annular window in the lid covering the foil with inner and outer diameters of respectively $8 \mathrm{~mm}$ and $10 \mathrm{~mm}$. Resulting signals were fitted with analytical equations for the diffusion problem [40,41], but since the foils were very thin the axial contribution and the finite extension of the window were found negligible, reducing the computation time. Heat losses were accounted for by multiplying with an exponential decay term described by Cowan. $[42,43]$

This method implies some experimental difficulties when foils with relatively low diffusivity are measured. Between $200{ }^{\circ} \mathrm{C}$ and $300^{\circ} \mathrm{C}$, their signals start exhibiting an offset at the time of the pulse incidence, which is followed by an atypical shape of the theoretically predicted temperature signals. This might supposedly be due to an increasingly larger thermal expansion [44] of the illuminated spot upon absorption of the laser pulse, possibly followed by a sudden deformation of the foil, which subsequently relaxes slowly into its original shape. Since the signal is detected optically, any time-dependent change in orientation of reflective and emitting surfaces is observed as a deviation in the signal. While the initial offset can be subtracted, the time-dependent changes are difficult to correct. Since foils with relatively high diffusivity exhibit a $\lambda \sim T^{-1}$-dependence between $30{ }^{\circ} \mathrm{C}$ and $700{ }^{\circ} \mathrm{C}$, which is also the case for foils with lower diffusivity up to $200{ }^{\circ} \mathrm{C}$ or $300{ }^{\circ} \mathrm{C}$, a $\lambda \sim T^{-1}$-dependence is extrapolated to higher temperatures for all foils for which these difficulties occurred.

The thermal conductivity is calculated via $\kappa=\lambda \times c_{\mathrm{p}} \times \rho$. The density $\rho$ was measured exploiting the Archimedes' principle. The specific heat $c_{\mathrm{p}}$ was taken from the literature [45], neglecting possible contributions from doping and nanocrystallinity.[46,47] The synthesis-method itself should not have an impact on the specific heat.[48]

\section{Results and Discussion}

\subsection{Chemical Composition and Microstructure}

As depicted in Figure 2a), the overall fraction of boron incorporated into the foils $X_{\mathrm{B} \text {,foil }}$ as determined by GDOES increases with an increasing fraction of boron $X_{\mathrm{B} \text {,gas }}$ present in the gas phase 

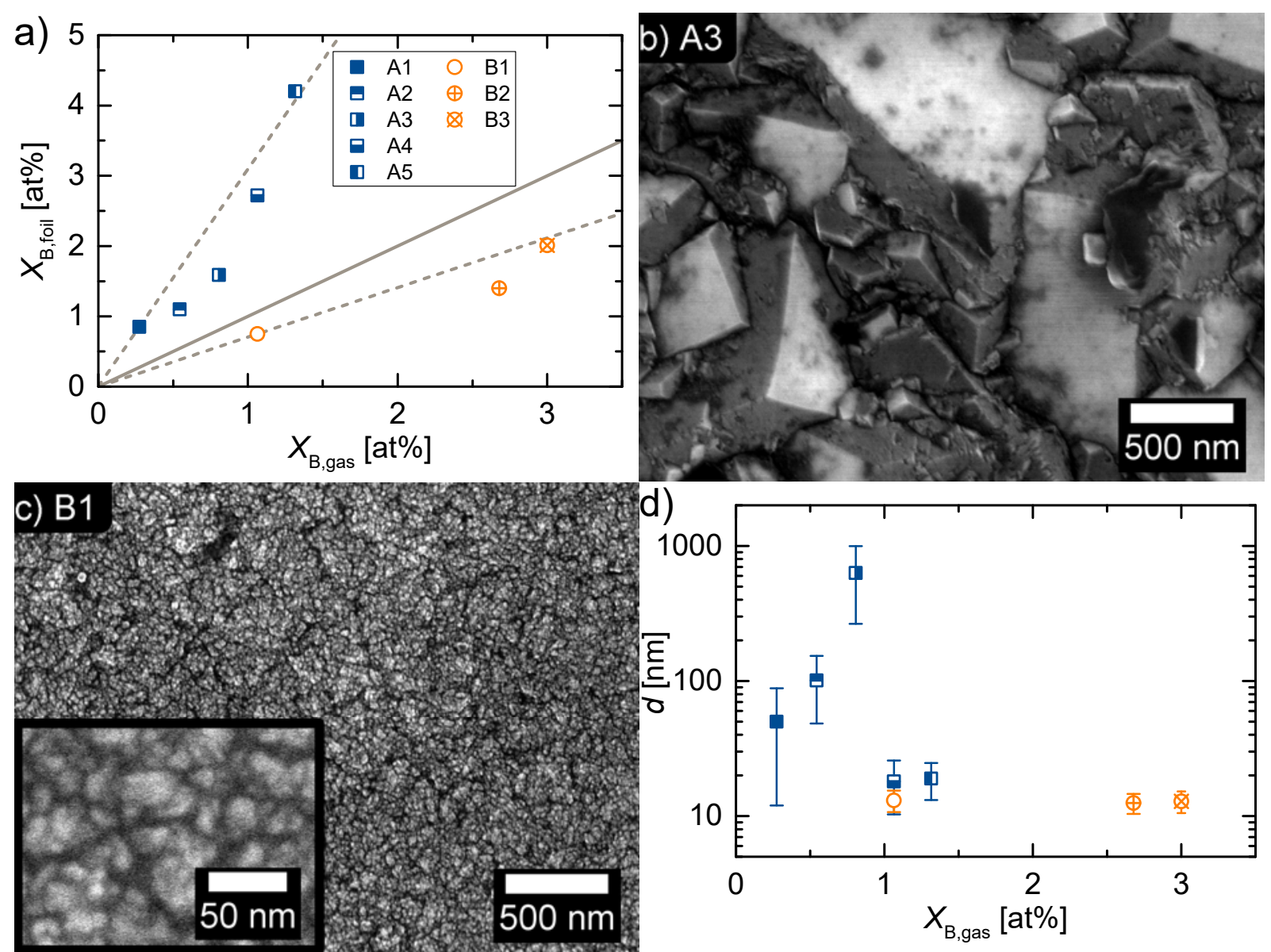

Figure 2. a) The overall fraction of boron in the foils $\left(X_{\mathrm{B}, \text { foil }}\right)$ increases with the fraction of boron present in the deposition process $\left(X_{\mathrm{B}, \mathrm{gas}}\right)$. If boron was incorporated into the foils in the same ratio as it is present in the gas phase, the solid line would result. It is higher in reactor A and lower in reactor $\mathrm{B}$, represented by dashed lines given as guides to the eye, normalized to the ratios $X_{\mathrm{B}, \text { foil }} / X_{\mathrm{B}, \mathrm{gas}}$ of foils $\mathrm{A} 1$ and $\mathrm{B} 1$. In both reactors, the ratio of incorporated boron is reduced at respective medium precursor fractions. b) and c) Scanning electron micrographs of the growth sides (top-view) of the rather microcrystalline foil A3 and respectively the nanocrystalline foil B1. d) The average grain diameter $d$ increases massively with increasing boron fraction in the gas phase $\left(X_{\mathrm{B}, \mathrm{gas}}\right)$, but drops to below $20 \mathrm{~nm}$ when $X_{\mathrm{B}, \text { gas }}$ exceeds about 0.9 at\%. In the foils from reactor $\mathrm{B}, \mathrm{a}$ mean grain diameter of about $13 \mathrm{~nm}$ is found.

during the manufacturing. $X_{\mathrm{B}, \mathrm{gas}}$ is calculated from the volume fractions of borate and methane. Due to the complexity of the reactions of all species involved, this relationship is not linear, which means that the ratio $X_{\mathrm{B} \text {,foil }} / X_{\mathrm{B}, \text { gas }}$ is not constant. In reactor $\mathrm{A}$, it is observed that $X_{\mathrm{B} \text {,foil }} / X_{\mathrm{B} \text {,gas }}$ is about the same for the foils A1 and A5, whereas in the case of the foil A3 it is reduced considerably. Foils A1 to A5 incorporate boron in a higher ratio than is present in the gas phase. The foils from reactor B show a much lower ratio, but they follow the trend that, at medium boron precursor concentration (B2), the ratio of incorporated boron is lower compared to foils B1 and B3.

Figure $2 \mathrm{~b}$ ) shows a top-view scanning electron micrograph of the microcrystalline diamond foil A3 featuring larger grains with prominent facets and smaller grains whose growth has been interrupted shortly after their secondary nucleation. Such features were not observed in the nanocrystalline foils B1 (see Figure 2c)), in which the apparent grain size is much more homogeneous and the edges appear much smoother than in the micrographs of foil A3.

The result of the quantification of the grain diameter is presented in Figure 2d). In reactor A, a boron fraction in the gas phase of up to about 0.9 at $\%$ leads to increasingly large grains. Together 


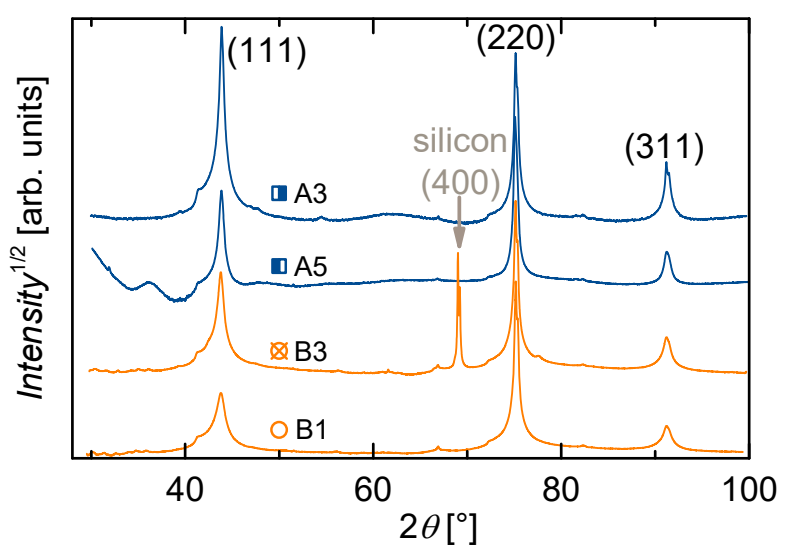

Figure 3. X-ray diffractograms of foils A3, A5, B1 and B3 after subtraction of the background. The (220) peak is normalized to the same intensity for all foils. The pattern of foil A5 is shifted at low angles due to a polyimide foil covering the diamond foil during data acquisition. The (400) peak from silicon in the pattern of foil B3 is an artifact from a dent in the silicon specimen holder, which is accounted for by an additional, highly textured Si phase in the Rietveld refinement of foil B3. Since the refined data fit the measured data very well, the influence of the artifacts on the results is assumed to be negligible.

with the results from Figure 2a), it can be noted that this grain growth is accompanied by a smaller ratio $X_{\mathrm{B}, \text { foil }} / X_{\mathrm{B} \text {,gas }}$ possibly due to the fast growth of diamond grains and their lower boron solubility compared to grain boundaries. It may be suspected that foils with such a reduced ratio contain a reduced fraction of grain boundaries. For larger boron fractions, as in A4 and A5, the grain diameter amounts to slightly less than $20 \mathrm{~nm}$. All foils in reactor B were manufactured at boron fractions above 1.0 at $\%$, and comparatively small grains of about $13 \mathrm{~nm}$ in diameter are observed independently of the boron precursor concentration. If the observation of a reduced ratio $X \mathrm{~B}$,foil $/ X_{\mathrm{B} \text {,gas }}$ actually leads to a reduced volume fraction of grain boundaries as suspected for the foils from reactor A, this assumption may also hold true for foil B2 despite its small grain size. The grain size in foils from reactor B exhibits greater homogeneity than in foils from reactor A, which can be judged based on the standard deviation given as error bars in Figure 2d).

X-ray diffractograms of select foils are given in Figure 3. Besides diamond, no other major crystalline phase is observed. The diminution of the (111) and (311) peaks is caused by the strong texturing. Their broadening is attributed to the presence of small, polycrystalline grains with random orientation. Columnar grains are assumed to be (220)-orientated. Foils A3 and B1 respectively exhibit the smallest and the largest anisotropy amongst the foils. In principle, it is also possible to obtain grain diameters from Rietveld refinements, but in our case the obtained values rather represent the spatial extension of the grains perpendicular to the direction of the characterization of the thermoelectric transport properties and the diameter estimated from SEM. An in-depth discussion of the anisotropy and the quantitative results for the grain sizes is included in the Supplementary Data, as well as Raman spectra of all foils (see Figure S1). From the Raman spectra, we conclude the presence of extended states of boron-doped diamond (broad bands centered at $500 \mathrm{~cm}^{-1}$ and $1225 \mathrm{~cm}^{-1}$ ), sp $\mathrm{sp}^{2}$-carbon (D- and G-bands at $1350 \mathrm{~cm}^{-1}$ and $1580 \mathrm{~cm}^{-1}$ ) and trans-polyacetylene-like structures (shoulders at $1150 \mathrm{~cm}^{-1}$ and $1450 \mathrm{~cm}^{-1}$, most pronounced in foil B1). [49,50]

With respect to thermoelectric transport we suppose that the properties appear to be rather isotropic within the plane while they will differ from the properties in the growth direction. Since only the in- 
plane thermoelectric transport properties were measured, the following discussion of the transport phenomena will exclusively refer to the in-plane microstructural features.

\subsection{Thermoelectric Transport Properties}

\subsubsection{Seebeck coefficient and charge carrier concentration}

Figure 4a) shows the Seebeck coefficient of all foils in dependence on the temperature. First of all, values well above $100 \mu \mathrm{V} \mathrm{K}^{-1}$ at high temperature are measured. The foil with the lowest boron fraction possesses the highest Seebeck coefficient, and vice versa. A mostly linear behavior is found for all foils. Such linearity is often observed in highly doped, degenerate semiconductors which exhibit metal-like transport. The temperature dependence is usually described by Equation (2).[2]

$$
\alpha(T)=\frac{8 \cdot \pi^{2} \cdot k_{\mathrm{B}}^{2}}{3 \cdot e \cdot h^{2}} \cdot m^{*} \cdot T \cdot\left(\frac{\pi}{3 \cdot p}\right)^{2 / 3}
$$

When inserting the Boltzmann constant $k_{\mathrm{B}}$, Planck's constant $h$ and the elementary charge $e$, the slope $\partial \alpha / \partial T$ can be used to evaluate for the charge carrier concentration $p$ if the density-of-states (DOS) effective mass $m *$ is constant in the considered temperature range.[51] We used $m^{*}=0.8 m_{0}$, but literature values vary.[52] The evaluation of the slope then yields the charge carrier concentration and can be taken as a measure for doping efficiency $p / X_{\mathrm{B} \text {,foil. }}$ In the case of highly doped nanostructured silicon, the numerical result obtained by this analysis has been shown to match the result of a Hall experiment quite well.[51]

The results of such an evaluation are represented in Figure 4b): the charge carrier concentration is depicted as a function of the boron fraction as measured by GDOES. It is to be noted that this method is not sensitive to the chemical and electronical surroundings of the analyzed species so that the boron fraction is not directly correlated to the charge carrier concentration. In theory, upon the introduction of slight amounts of boron into phase-pure diamond, one would expect that every boron atom accepts one electron. This ideal situation is represented by the leftmost dashed line with a slope equal to unity. The charge carrier concentration is assumed to become constant when the solubility limit (0.28 at\% [34]) is reached and excess boron may take interstitial positions or precipitate into foreign phases depending on the conditions during the deposition process.
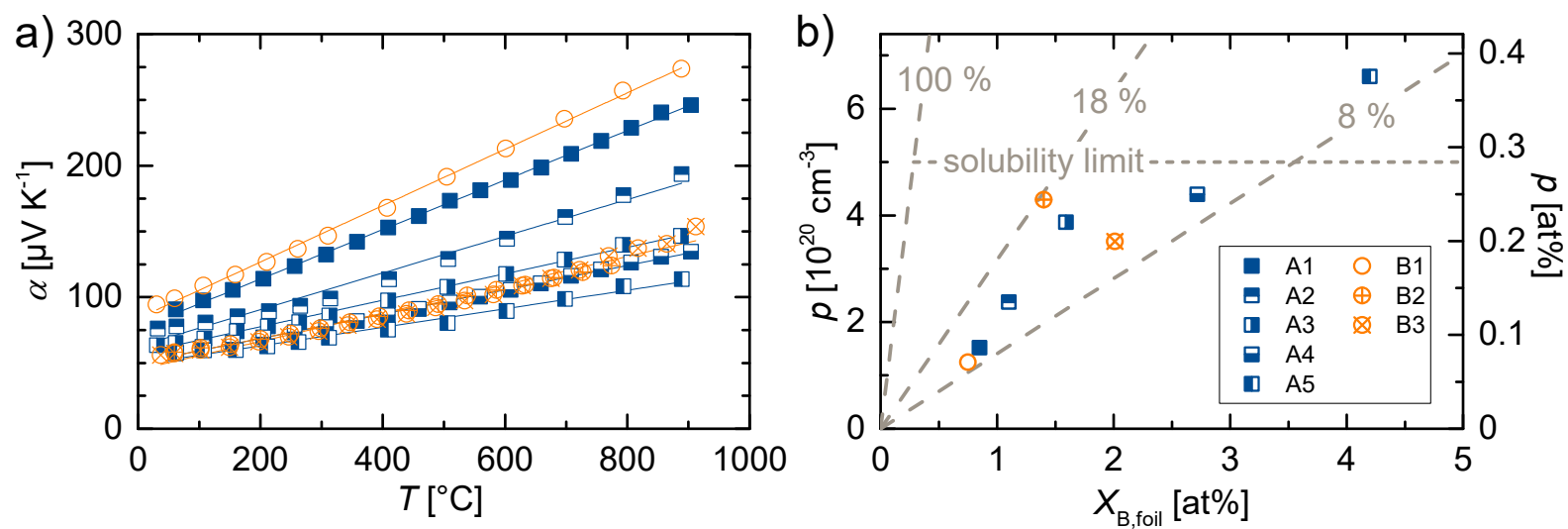

Figure 4. a) The Seebeck coefficients of all foils increase mostly linearly with the temperature, as indicated by linear fits. b) The slope of these fits is evaluated for the charge carrier concentration $p$ and the result is presented as a function of boron fraction in the foils $\left(X_{\mathrm{B}, \text { foil }}\right)$. Dashed lines indicate

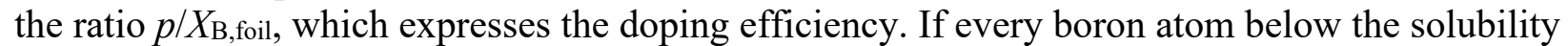
limit was incorporated substitutionally, the charge carrier concentration should amount to about $5 \times 10^{20} \mathrm{~cm}^{-3}$. Instead, ratios between $8 \%$ and $18 \%$ are found. 
The dashed lines in Figure $4 \mathrm{~b}$ ) indicate the cases that $8 \%, 18 \%$ or $100 \%$ of boron atoms serve as acceptors. The foils A3 and B2 exhibit the highest doping efficiencies amongst all foils. Interestingly, these two foils are the ones with the lowest incorporation of boron compared to the volume fraction of boron precursor gas during manufacturing (see Figure 2a)). Thus, boron seems to be more difficult to incorporate under the given conditions, but once a boron atom is bound it is more likely to find a chemical surrounding where it accepts an electron, supposedly at a substitutional site in a diamond grain.

The overall low doping efficiency is an indication that the majority of boron atoms prefers other locations to substitutional lattice sites. It may be suspected that efficient doping is increasingly difficult with an increasingly complex microstructure where plenty of possibly preferable sites for boron are present. Especially, the formation of foreign phases may be expected at grain boundaries. Conceivable phases include elemental boron, boron carbides of any stoichiometry and boron-doped $\mathrm{sp}^{2}$-carbon, all of which exhibit $p$-type behavior.[53-55] Since an undoped, nanocrystalline foil manufactured using comparable conditions exhibits a high, positive Seebeck coefficient and a much lower electrical conductivity (see Figure S2 in the Supplementary Data), it can be supposed that a carbon matrix phase majorly contributing to electrical transport [30] does not have a significant influence on the transport in our nanocrystalline diamond. However, it cannot be excluded that upon boron-doping, boron-rich grain boundary material may significantly contribute to electrical conduction as has been hypothesized for high-temperature, high-pressure diamond.[33] The absence of possible $n$-type contributions and the linear dependence of the Seebeck coefficient on temperature support the applicability of Equation (2), and the estimated charge carrier concentrations are in a range where metal-like transport can be considered as a valid possible mechanism.

\subsubsection{Electrical conductivity and mobility}

The electrical conductivity is often described in the simple form of Equation (3). $\sigma=p \cdot e \cdot \mu$

In this form, the conductivity is determined by the charge carrier concentration and their average mobility $\mu$. Completely degenerate semiconductors usually exhibit a decreasing electrical conductivity with increasing temperature, which is ascribed to a decrease in mobility due to acoustic phonon scattering whereas the charge carrier concentration stays constant.

However, in this case we observe a thermally activated conductivity in all foils as depicted in an Arrhenius plot (see Figure 5a)), a behavior that is not typical for metal-like transport. A similar behavior can be found, e.g., in highly doped nanograined $\mathrm{ZnO}$ [56], where it is explained with grain boundary scattering. [57,58] The microstructure influences the electrical conductivity much more than the Seebeck coefficient.[56,59] Nam et al. measured a linear dependence of the Seebeck coefficient on the temperature and a temperature independent charge carrier concentration despite a strong thermal activation of the electrical conductivity, assigning the activation to an increase in mobility when the grain boundary barrier height surpasses the difference between the Fermi level and the bottom of the conduction band.[56]

A thermal activation by a factor of four is observed in foil B1, which exhibits the lowest electrical conductivity over the whole temperature range. The foil with the highest electrical conductivity (A3) exhibits an increase of only $15 \%$. The factors determining the electrical conductivity appear to be complex. In order to get an impression in how far the microstructure influences the electrical 
a)

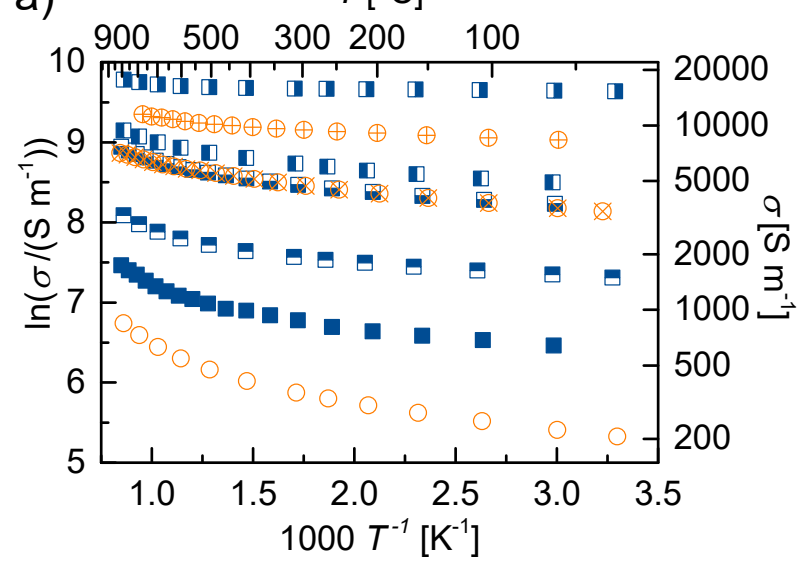

b)

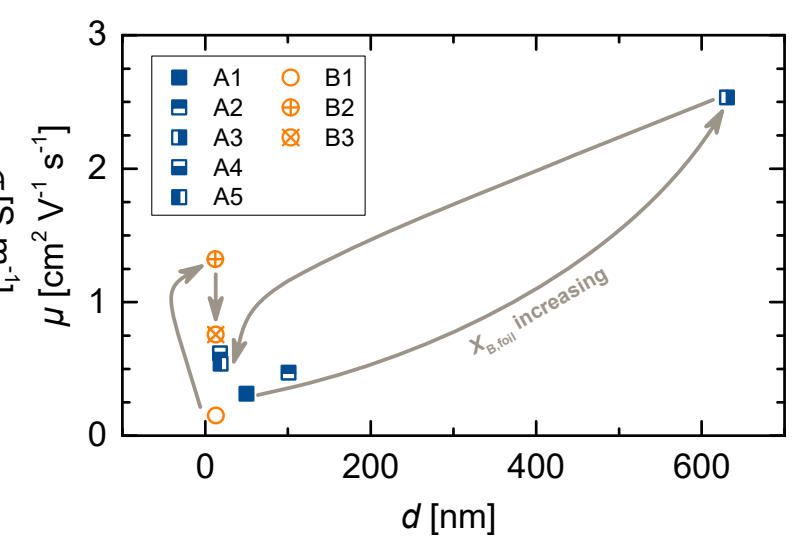

Figure 5. a) Arrhenius plot of the electrical conductivity. All foils exhibit a thermally activated conductivity, but the activation diminishes with increasing conductivity. b) The mobility at $200{ }^{\circ} \mathrm{C}$ does not only depend on the grain diameter, but exhibits complex dependencies on the manufacturing parameters.

conductivity, the mobility was calculated from the electrical conductivity at $200{ }^{\circ} \mathrm{C}$ using Equation (3), cancelling out the differences in charge carrier concentration.

The results presented in Figure 5b) reveal that most foils exhibit mobility values on the order of $1 \mathrm{~cm}^{2} \mathrm{~V}^{-1} \mathrm{~s}^{-1}$. Mobilities between $1 \mathrm{~cm}^{2} \mathrm{~V}^{-1} \mathrm{~s}^{-1}$ and $10 \mathrm{~cm}^{2} \mathrm{~V}^{-1} \mathrm{~s}^{-1}$ are considered to be on the verge between hopping and metal-like transport.[60] In this range, the transport process might have an intermediary character.[51] Since the Seebeck coefficient is less sensitive to the microstructure, it exhibits a degenerate behavior with metal-like character as concluded from the linear increase with temperature, whereas the electrical conductivity shows thermal activation, possibly caused by grain boundary scattering which reduces the mobility.

Clearly, the foil with the largest grains (A3) exhibits the highest mobility. However, the foils A4 and A5 possess a higher mobility than the foils A1 and A2 although their grain sizes are significantly smaller. The reason may be suspected in the grain boundary scattering, which not only depends on the density of boundaries, which is related to the grain size, but also on their width and composition, determining the barrier height.

This conclusion is substantiated by the variation in mobility found for the foils manufactured in reactor $\mathrm{B}$, which is quite large despite their similar grain size. E.g., articulate shoulders at $1150 \mathrm{~cm}^{-1}$ and $1450 \mathrm{~cm}^{-1}$ in the Raman spectrum of foil B1 (see Figure S1b) in the Supplementary Data) indicate significant amounts of trans-polyacetylene-like structures at the grain boundaries [50], which may partly explain the low mobility in this foil. Unfortunately, Raman spectroscopy does not reveal more detailed information on the nature of the grain boundaries, and X-ray diffractograms do not show a major fraction of crystalline boron or boron-rich phases even in the foil with the highest boron fraction.

The increased doping efficiency (see Figure 4b)) of foils A3 and B2, which goes along with a reduced ratio $X_{\mathrm{B}, \text { foil }} / \mathrm{X}_{\mathrm{B} \text {,gas }}$ (see Figure $2 \mathrm{a}$ )), seems to allow for the assumption that the volume fraction of the diamond phase in these foils is increased and that the volume fraction of grain boundaries and their width are decreased. These observations go along with the comparatively low thermal activation and the highest mobilities found in these foils.

The mobility turns out to largely govern the electrical conductivity and also the power factor. E.g., at $890{ }^{\circ} \mathrm{C}$ the microcrystalline foil $\mathrm{A} 3$ possesses a mobility of $2.9 \mathrm{~cm}^{2} \mathrm{~V}^{-1} \mathrm{~s}^{-1}$ and a power factor of 
$0.38 \mathrm{~mW} \mathrm{~m}^{-1} \mathrm{~K}^{-2}$. The nanocrystalline foil $\mathrm{B} 3$ achieves $0.14 \mathrm{~mW} \mathrm{~m}^{-1} \mathrm{~K}^{-2}$ with a mobility of $1.2 \mathrm{~cm}^{2} \mathrm{~V}^{-1} \mathrm{~s}^{-1}$ at this temperature. These power factors are quite decent, especially upon consideration of the rather low mobility.

\subsubsection{Jonker-type analysis}

Another method to evaluate the thermoelectric potential of a material is the Jonker-type analysis that was initially proposed for small band gap and non-degenerate semiconductors.[61] Later, it was also applied to highly doped oxides with large band gaps.[62,63] Since electron conduction can be neglected in large band gap hole conductors, the Seebeck coefficient in different specimens of a material with varying charge carrier concentration depends linearly on the natural logarithm of their respective electrical conductivity as described by Equation (4).

$$
\alpha=-\frac{k_{\mathrm{B}}}{e} \ln \sigma+\frac{k_{\mathrm{B}}}{e} \ln \left(N_{\mathrm{v}} \cdot e \cdot \mu \cdot \exp A\right)
$$

The summand can be regarded as a constant if the effective valence band DOS $N_{\mathrm{v}}$, the transport mechanism (described by the transport constant $A$ ), and the mobility are unaffected by changing the dopant concentration. Consequently, $\ln \left(N_{\mathrm{v}} \times e \times \mu \times \exp A\right)$ is expressed as $\ln \sigma_{0}$. [62]

Figure 6 shows a Jonker-plot with a linear fit of fixed slope $-k_{B} / e=-86.2 \mu \mathrm{V} \mathrm{K}^{-1}$, from which $\ln \sigma_{0}$ is directly obtained as its $x$-axis intercept. In this type of analysis, the maximum power factor is always found at a Seebeck coefficient of $\alpha=2 \times k_{\mathrm{B}} / e=172.3 \mu \mathrm{V} \mathrm{K}^{-1}$ and an electrical conductivity of $\ln \sigma=\ln \sigma 0-2$.[63,64] That means the charge carrier concentration needs to be adjusted accordingly. Obviously, shifting $\ln \sigma 0$ to higher values yields higher maximum power factors. Such a shift is achieved by enhancing the so-called DOS-mobility-product $N_{\mathrm{v}} \times \mu$ [65] by, e.g., tailoring the microstructure in a fashion that the mobility increases.

Löfås et al. calculated Seebeck coefficients from experimental values for electrical conductivity and Hall coefficients of single crystalline CVD diamond.[19] A Jonker-type analysis of these data yields $\ln \sigma_{0}=15.1$. This value is comparable to state of the art thermoelectric materials due to the very high mobility of charge carriers in single-crystalline diamond $\left(1200 \mathrm{~cm}^{2} \mathrm{~V}^{-1} \mathrm{~s}^{-1}\right.$ [32]), demonstrating the potential of the material. At optimum carrier concentration, the power factor of this material amounts to $14 \mathrm{~mW} \mathrm{~m}^{-1} \mathrm{~K}^{-2}$ at room temperature. It has to be noted though that a reduction of the

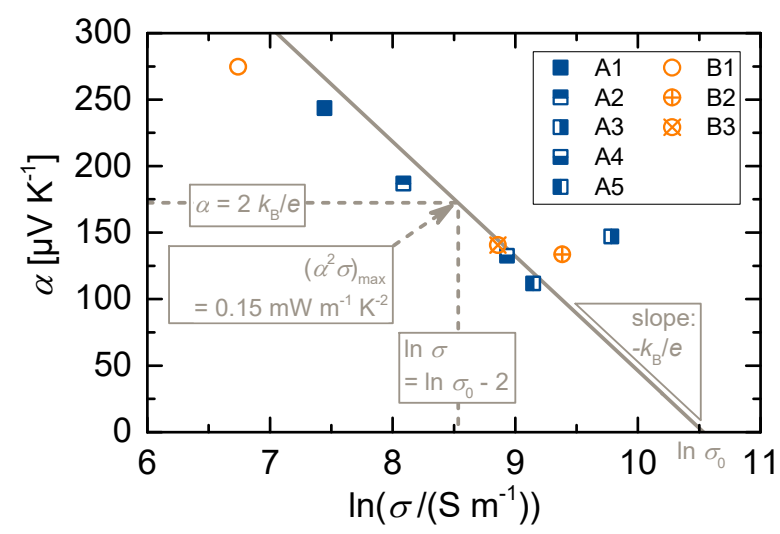

Figure 6. Jonker-plot at $890^{\circ} \mathrm{C}$. A linear fit with fixed slope of $-k_{\mathrm{B}} / e$ yields $\ln \sigma_{0}=10.5$, which is mainly determined by the DOS-mobility-product of a certain material including its microstructure. For $\ln \sigma_{0}=10.5$, at optimum doping concentration a maximum power factor of $0.15 \mathrm{~mW} \mathrm{~m}^{-1} \mathrm{~K}^{-2}$ is achievable. The foil A3 deviates most from the linear relationship due to its higher DOS-mobilityproduct, leading to a higher power factor $\left(0.38 \mathrm{~mW} \mathrm{~m}^{-1} \mathrm{~K}^{-2}\right.$ at $\left.890{ }^{\circ} \mathrm{C}\right)$. 
thermal conductivity by orders of magnitude is difficult to achieve without reducing the mobility of charge carriers.

That is the reason why the diamond foils presented in Figure 6 achieve a significantly lower $\ln \sigma_{0}=10.5$, leading to a reduction in the possible maximum power factor to $0.15 \mathrm{~mW} \mathrm{~m} \mathrm{~K}^{-2}$ along the fitted line. Deviations from the linear relationship are directly correlated with the mobility as shown in Figure 5b). Comparatively low mobilities (foils A1, A2, B1) lead to a lower DOS-mobility-product, decreasing $\ln \sigma 0$ and shifting data points in a Jonker-plot to the left. The opposite is the case for the foils A3 and B2 with comparatively high mobilities and this is directly expressed in a comparatively high power factor.

It may be noted that the Jonker-type analysis in this case of a highly doped large band gap semiconductor delivers valid results only at a high temperature because the transport is less restricted by grain boundary scattering as required by the assumptions that do not account for microstructural properties. Our foils are comparable to each other, but it can be seen that the results are quite sensitive to the manufacturing parameters and properties of the foils.

\subsubsection{Thermal conductivity and figure of merit}

Figure 7a) shows the thermal conductivity of the foils. At high temperature, values between $24 \mathrm{~W} \mathrm{~m}^{-1} \mathrm{~K}^{-1}$ and $57 \mathrm{~W} \mathrm{~m}^{-1} \mathrm{~K}^{-1}$ are extrapolated. This strong reduction compared to single crystalline diamond is a result of the microstructure that is responsible for phonon scattering at grain boundaries.

Due to the high Debye temperature of diamond, its heat capacity increases strongly even above room temperature. Although the thermal diffusivity decreases with increasing temperature, this leads to an increasing thermal conductivity. The general trend that a smaller average grain size leads to lower thermal conductivity and a shift in its maximum to higher temperatures was described before. $[66,67]$ In our case, the thermal conductivity is comparatively low so that the maximum is shifted to temperatures above $900{ }^{\circ} \mathrm{C}$. This effect is opposite to what is usually observed in materials for thermoelectric application. In addition, from the viewpoint of thermoelectrics, the thermal conductivity is still quite high despite the significant reduction.

The extrapolation of the data from the lower temperature range may produce significant errors at high temperature. E.g., comparing foils A1 and A5, a crossover at about $300{ }^{\circ} \mathrm{C}$ is observed, and the thermal conductivity of foil A1 may be assumed to be underestimated by several $\mathrm{W} \mathrm{m}^{-1} \mathrm{~K}^{-1}$ at $900{ }^{\circ} \mathrm{C}$ as judged from the evolution of the thermal conductivity of most other foils with temperature. The error propagation in the calculation of the figure of merit at high temperature may lead to an overestimation of zT by 15 to $20 \%$ if this assumption holds true. Figure $7 \mathrm{~b}$ ) relates the thermal conductivity at $200{ }^{\circ} \mathrm{C}$ to the grain size. The foils manufactured in reactor A appear to largely correlate with the grain diameter. In the foils with a mean grain size below $20 \mathrm{~nm}$ the correlation diminishes supposedly due to the larger volume fraction of the grain boundaries. The variation in thermal conductivity at comparably small grain size therefore demonstrates the influence of the width and composition of the grain boundaries. A comparison with the mobility of the foils (see Figure 5b)) leads to the conclusion that the influence of the grain boundaries on phonon transport differs a lot from their influence on hole transport. E. g., if the assumption of trans-polyacetylene-like structures in foil B1 holds true, such structures reduce charge carrier mobility much more than thermal conductivity. This conclusion points to the necessity of controlling the exact nature of the grain boundaries. The dimensionless thermoelectric 

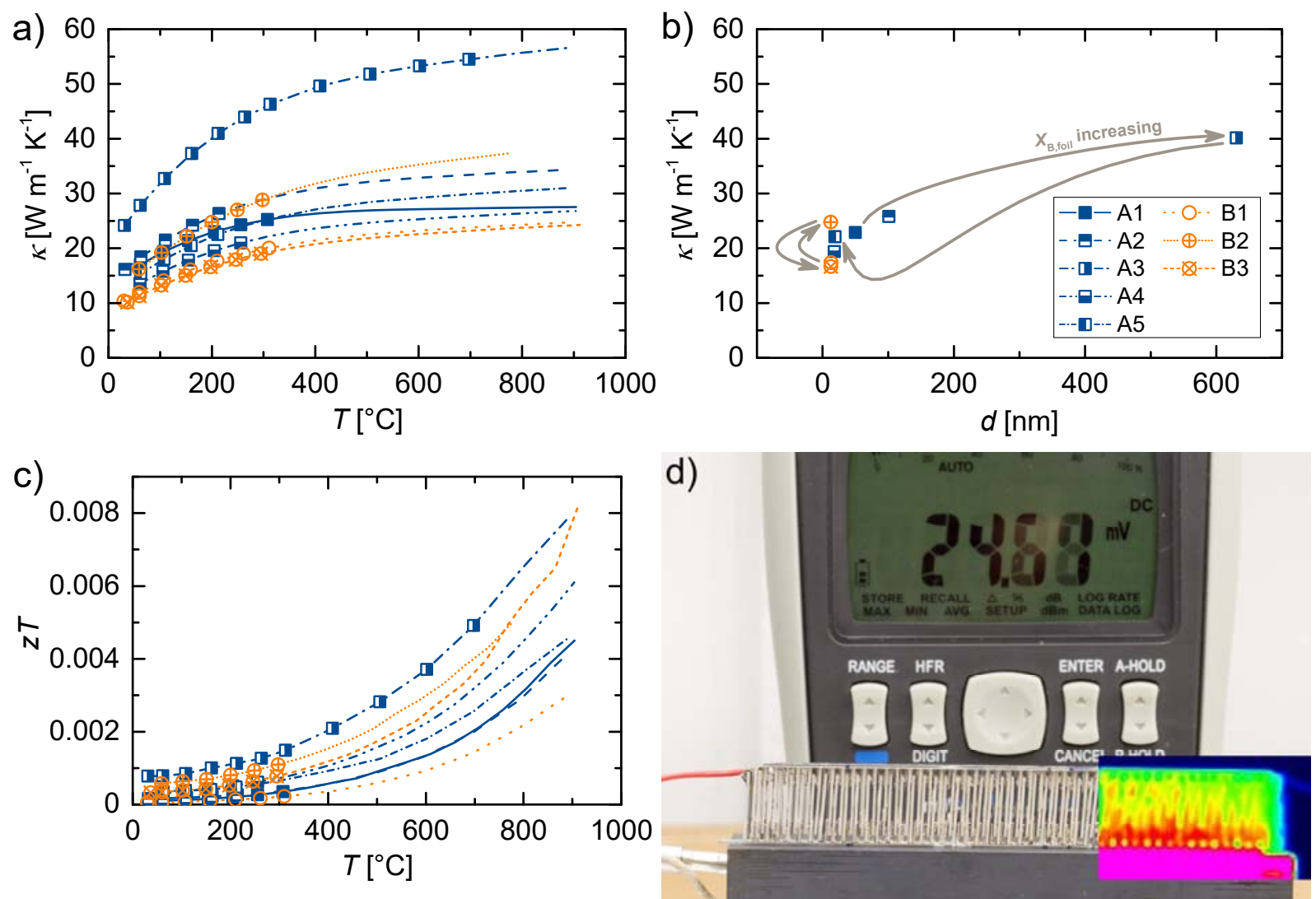

Figure 7. a) The thermal conductivity of all foils was measured up to at least $200{ }^{\circ} \mathrm{C}$ (symbols) and extrapolated to high temperatures (lines, see methodology described in section 3.3). b) The thermal conductivity at $200{ }^{\circ} \mathrm{C}$ as a function of grain diameter allows for a comparison of the foils. A reduction in grain size leads to a decrease in thermal conductivity. c) The dimensionless thermoelectric figure of merit $z T$ in dependence on temperature as calculated from measured power factors and measured or extrapolated thermal conductivities. d) Photograph and thermal image of a prototype thermoelectric module on a hot stage at $75^{\circ} \mathrm{C}$ generating an open circuit voltage of $25 \mathrm{mV}$.

figure of merit $z T$ of the foils is depicted in Figure 7c) in dependence on temperature. The highest figure of merit of about 0.008 at $900{ }^{\circ} \mathrm{C}$ is achieved in foils with comparatively high (A3) or at least medium (B2, B3) power factor, whereas the thermal conductivity exhibits a medium value (B2), the lowest (B3) or the highest (A3) observed value. However, in all these foils the boron fraction is between 1.4 at $\%$ and 2.0 at $\%$. Despite quite decent power factors, the figure of merit is evidently very low due to the low mobility and high thermal conductivity. After optimization of the properties with special regard to the width, chemical composition and structure of the grain boundaries, certain niche applications with the desire for a very robust material are conceivable.

The applicability of foils for thermoelectric power conversion is demonstrated in Figure 7d). A prototype module was built from $48 p$-type diamond and $48 n$-type constantan foils $\left(3 \times 12 \mathrm{~mm}^{2}\right.$ each). The foils are mechanically supported by alumina substrates and electrically connected in series by metal foils and a brazing solder containing silver and titanium. Aluminum nitride ceramics serve as top and bottom substrates. On a hot stage at $75{ }^{\circ} \mathrm{C}$ in ambient atmosphere this module generates an open circuit voltage of $25 \mathrm{mV}$ without additional cooling as can be seen from the photograph. The thermal image reveals that a major part of the supplied heat flows into the vertical 
substrates, which reduces the temperature difference along the foils, but the gaps prevent a direct thermal short-circuit.

\section{Conclusion}

Although some indications and motivation are given in the literature that diamond could be of interest for thermoelectric power conversion, experimental data are rare. Our study is the first to present Seebeck coefficient and thermal conductivity data for a set of several nanocrystalline selfsupporting diamond foils from chemical vapor deposition in a wide temperature range between room temperature and $900{ }^{\circ} \mathrm{C}$.

The Seebeck coefficient exceeds $100 \mu \mathrm{V} \mathrm{K}^{-1}$ in all foils at high temperature, leading to decent power factors exceeding $0.1 \mathrm{~mW} \mathrm{~m}^{-1} \mathrm{~K}^{-2}$. Unlike other carbon-based materials, such as graphite [68], nanocarbon ensembles [69] or graphitic boron carbon nitride $\left(\mathrm{BC}_{3} \mathrm{~N}\right)$ [70], diamond achieves a considerable Seebeck coefficient. From its temperature dependence a metal-like transport is concluded for our foils, whereas the dependence of the electrical conductivity on temperature exhibits a thermally activated transport, which may be explained with grain boundary scattering. At high temperature, the charge carriers seem to possess enough thermal energy to move more freely, allowing for a Jonker-type analysis.

Since all transport coefficients were characterized in-plane (perpendicularly to the growth direction) it is valid to calculate the dimensionless thermoelectric figure of merit $z T$. The resulting values are lower than $z T=0.01$ even at high temperature, which is ascribed to the low mobility of charge carriers (about $1 \mathrm{~cm}^{2} \mathrm{~V}^{-1} \mathrm{~s}^{-1}$ ) and to the high thermal conductivity (between $20 \mathrm{~W} \mathrm{~m}^{-1} \mathrm{~K}^{-1}$ and $60 \mathrm{~W} \mathrm{~m}^{-1} \mathrm{~K}^{-1}$ ). Despite some uncertainties in the quantitative assessment of grain diameters from top-view scanning electron micrographs at the foils' growth sides, this method has been found to be a helpful tool for an evaluation of the influence of the microstructure on the transport properties. These correlations between transport properties and the microstructure reveal that not the grain size alone influences the transport of charge carriers and phonons, but also the nature of the grain boundaries. That is why it is reasonable to assume that a reduction of grain boundary width, and therefore their volume fraction, may lead to a significant improvement in the mobility. One way to control the formation of $\mathrm{sp}^{2}$-carbon is to limit the conversion of ethyne into trans-polyacetylene-like chains by use of hydrogen radicals. Another way would aim for a higher rate of substitutional incorporation of boron into the diamond lattice despite its low solubility.

A further reduction of the grain size seems a plausible approach to decrease the thermal conductivity. It should be noted though that this approach implicates challenges concerning the prevention of an increase in the fraction of $\mathrm{sp}^{2}$-carbon, which preferentially forms at grain boundaries, and challenges concerning the substitutional incorporation of boron into the diamond lattice when there are plenty of other sites. A method to reduce the thermal conductivity without affecting the charge carrier transport is the synthetic enrichment of diamond with ${ }^{13} \mathrm{C}$ isotopes.[71,72]

\section{Acknowledgements}

We thank Felix Schmidt (Faculty of Physics, University of Duisburg-Essen), Peter Schoderböck (Plansee SE) and André Lindemann (Netzsch-Gerätebau GmbH) for support and discussion regarding laser flash in-plane measurements and data evaluation. Timo Fromm and Benjamin Reiß (WTM, University of Erlangen-Nuernberg) are thanked for designing the schematics of the 
measurement setups. Rudolf Borchardt (WTM, University of Erlangen-Nuernberg) is thanked for building and acquiring images of the prototype thermoelectric module.

The authors gratefully acknowledge financial support in the framework of a young investigator grant by the Ministry of Innovation, Science and Research of the State of North Rhine-Westphalia, as well as funding by the German Research Foundation (DFG: RO2366/7-1) and by the Bavarian

State Government (MATSOL, Energy Campus Nuernberg, EnCN).

\section{References}

[1] Hicks LD, Dresselhaus MS. Effect of quantum-well structures on the thermoelectric figure of merit. Phys. Rev. B 1993; 47(19):12727-31. doi:10.1103/PhysRevB.47.12727.

[2] Snyder GJ, Toberer ES. Complex Thermoelectric Materials. Nat. Mater. 2008; 7(2):105-14. doi:10.1038/nmat2090.

[3] Martin J, Wang L, Chen L, Nolas GS. Enhanced Seebeck coefficient through energy-barrier scattering in PbTe nanocomposites. Phys. Rev. B 2009; 79(11):115311. doi:10.1103/PhysRevB.79.115311.

[4] Lan Y, Minnich AJ, Chen G, Ren Z. Enhancement of Thermoelectric Figure-of-Merit by a Bulk Nanostructuring Approach. Adv. Funct. Mater. 2010; 20(3):357-76. doi:10.1002/adfm.200901512.

[5] Kachold FS, Lodes MA, Rosiwal SM, Singer RF. Direct measurement of Young's modulus, fracture strength and fracture toughness of nanocrystalline diamond foil by means of tensile testing. Acta Mater. 2013; 61(18):7000-8. doi:10.1016/j.actamat.2013.08.014.

[6] Revin OG. Seebeck effect in synthetic $p$-type diamonds. Sov. Phys. Semicond. 1987; 21(12):1341-2.

[7] Gruen DM. Electron Transport and the Potential of Ultrananocrystalline Diamond as a Thermoelectric Material. In: Shenderova OA, Gruen DM, editors. Ultrananocrystalline diamond: Synthesis, properties, and applications. Norwich, NY, USA: William Andrew; 2006, p. 157-184.

[8] Emin D. Effects of Charge Carriers' Interactions on Seebeck Coefficients. In: Rowe DM, editor. Thermoelectrics handbook: Macro to nano. Boca Raton, FL, USA: CRC Press; 2006, p. 5.1-5.7. doi:10.1201/9781420038903.ch5.

[9] Goldsmid HJ, Jenns CC, Wright DA. The Thermoelectric Power of a Semiconducting Diamond. Proc. Phys. Soc. 1959; 73(3):393-8. doi:10.1088/0370-1328/73/3/306.

[10] Eidelman ED, Vul' AY. The strong thermoelectric effect in nanocarbon generated by the ballistic phonon drag of electrons. J. Phys. Condens. Matter 2007; 19(26):266210. doi:10.1088/0953-8984/19/26/266210.

[11] Nolas GS, Sharp J, Goldsmid HJ. Thermoelectrics: Basic principles and new materials developments. Berlin, Germany: Springer; 2001. doi:10.1007/978-3-662-04569-5.

[12] Keyes RW. Low Temperature Peltier Cooling. In: Heikes RR, Ure RW, editors. Thermoelectricity: Science and Engineering. New York, NY, USA: Interscience Publishers; 1961, p. 389-404.

[13] Zhu W. Defects in Diamond. In: Pan LS, Kania, DR, editors. Diamond: electronic properties and applications. Boston, MA, USA: Kluwer; 1995. p. 175-239. doi:10.1007/978-1-46152257-7_5.

[14] Spitsyn BV, Bouilov LL, Derjaguin BV. Vapor growth of diamond on diamond and other surfaces. J. Cryst. Growth 1981; 52(1):219-26. doi:10.1016/0022-0248(81)90197-4. 
[15] Gildenblat GS, Grot SA, Badzian A. The electrical properties and device applications of homoepitaxial and polycrystalline diamond films. Proc. IEEE 1991; 79(5):647-68. doi:10.1109/5.90130.

[16] Poferl DJ, Gardner NC, Angus JC. Growth of boron-doped diamond seed crystals by vapor deposition. J. Appl. Phys. 1973; 44(4):1428-34. doi:10.1063/1.1662389.

[17] Balducci A, Marinelli M, Morgada ME, Pucella G, Rodriguez G, Scoccia M et al. CVDdiamond-based thermocouple for high sensitive temperature measurements. Microsyst. Technol. 2006; 12(4):365-8. doi:10.1007/s00542-005-0066-y.

[18] Horiuchi R, Okano K, Rupesinghe N, Chhowalla M, Amaratunga GAJ. Seebeck Measurements of N-Doped Diamond Thin Film. phys. stat. sol. (a) 2002; 193(3):457-61. doi:10.1002/1521-396X(200210)193:3<457:AID-PSSA457>3.0.CO;2-5.

[19] Löfås H, Grigoriev A, Isberg J, Ahuja R. Transport coefficients in diamond from ab-initio calculations. Appl. Phys. Lett. 2013; 102(9):092106. doi:10.1063/1.4794062.

[20] Gabrysch M, Majdi S, Hallén A, Linnarsson M, Schöner A, Twitchen D et al. Compensation in boron-doped CVD diamond. phys. stat. sol. (a) 2008; 205(9):2190-4. doi:10.1002/pssa.200879711.

[21] Okano K, Akiba Y, Kurosu T, Iida M, Nakamura T. Synthesis of B-doped diamond film. J. Cryst. Growth 1990; 99(1-4):1192-5. doi:10.1016/S0022-0248(08)80106-6.

[22] Masood A, Aslam M, Tamor MA, Potter TJ. Synthesis and electrical characterization of boron-doped thin diamond films. Appl. Phys. Lett. 1992; 61(15):1832-4. doi:10.1063/1.108389.

[23] Katamune Y, Ohmagari S, Setoyama H, Sumitani K, Hirai Y, Yoshitake T. Formation of pType Ultrananocrystalline Diamond/Nonhydrogenated Amorphous Carbon Composite Films Prepared by Coaxial Arc Plasma Deposition with Boron-Incorporated Graphite Targets. ECS Trans. 2013; 50(20):23-8. doi:10.1149/05020.0023ecst.

[24] Wörner E. Thermal Properties and Applications of CVD Diamond. In: Dischler B, Wild C, editors. Low-Pressure Synthetic Diamond: Manufacturing and applications. Berlin, Germany: Springer; 1998, p. 165-187. doi:10.1007/978-3-642-71992-9_9.

[25] Graebner JE, Jin S, Kammlott GW, Herb JA, Gardinier CF. Unusually high thermal conductivity in diamond films. Appl. Phys. Lett. 1992; 60(13):1576-8. doi:10.1063/1.107256.

[26] Graebner JE, Jin S, Kammlott GW, Herb JA, Gardinier CF. Large anisotropic thermal conductivity in synthetic diamond films. Nature 1992; 359(6394):401-3. doi:10.1038/359401a0.

[27] Kulisch W, Popov C, Sasaki T, Sirghi L, Rauscher H, Rossi F et al. On the development of the morphology of ultrananocrystalline diamond films. phys. stat. sol. (a) 2011; 208(1):70-80. doi:10.1002/pssa.201026066.

[28] Williams OA, Daenen M, D'Haen J, Haenen K, Maes J, Moshchalkov VV et al. Comparison of the growth and properties of ultrananocrystalline diamond and nanocrystalline diamond. Diamond Rel. Mater. 2006; 15(4-8):654-8. doi:10.1016/j.diamond.2005.12.009.

[29] Krüger A. Neue Kohlenstoffmaterialien: Eine Einführung. Wiesbaden, Germany: B.G. Teubner; 2007. doi:10.1007/978-3-8351-9098-6.

[30] Kulisch W, Popov C, Lefterova E, Bliznakov S, Reithmaier JP, Rossi F. Electrical properties of ultrananocrystalline diamond/amorphous carbon nanocomposite films. Diamond Rel. Mater. 2010; 19(5-6):449-52. doi:10.1016/j.diamond.2010.01.021. 
[31] Williams OA, Curat S, Gerbi JE, Gruen DM, Jackman RB. $n$-type conductivity in ultrananocrystalline diamond films. Appl. Phys. Lett. 2004; 85(10):1680-2. doi:10.1063/1.1785288.

[32] Sze SM, Ng KK. Physics of Semiconductor Devices. 3rd ed. Hoboken, NJ, USA: WileyInterscience; 2007. doi:10.1002/9780470068328.app6.

[33] Dubrovinskaia N, Wirth R, Wosnitza J, Papageorgiou T, Braun HF, Miyajima N et al. An insight into what superconducts in polycrystalline boron-doped diamonds based on investigations of microstructure. Proc. Natl. Acad. Sci. U.S.A. 2008; 105(33):11619-22. doi:10.1073/pnas.0801520105.

[34] Chen Y, Hu C, Lin I. Defect structure and electron field-emission properties of boron-doped diamond films. Appl. Phys. Lett. 1999; 75(18):2857-9. doi:10.1063/1.125173.

[35] Ramakrishnan R, Lodes MA, Rosiwal SM, Singer RF. Self-supporting nanocrystalline diamond foils: Influence of template morphologies on the mechanical properties measured by ball on three balls testing. Acta Mater. 2011; 59(9):3343-51. doi:10.1016/j.actamat.2011.02.009.

[36] Lodes MA, Rosiwal SM, Singer RF. Self-Supporting Nanocrystalline Diamond Foils - A New Concept for Crystalline Diamond on any Technical Surface. Key Eng. Mater. 2010; 438:163-9. doi:10.4028/www.scientific.net/KEM.438.163.

[37] Iwanaga S, Toberer ES, LaLonde A, Snyder GJ. A high temperature apparatus for measurement of the Seebeck coefficient. Rev. Sci. Instrum. 2011; 82(6):063905. doi:10.1063/1.3601358.

[38] Lutterotti L, Chateigner D, Ferrari S, Ricote J. Texture, residual stress and structural analysis of thin films using a combined X-ray analysis. Thin Solid Films 2004; 450(1):34-41. doi:10.1016/j.tsf.2003.10.150.

[39] Matej Z, Nichtova L, Kuzel R. Microstructural characterization of nanocrystalline powders and thin films by X-ray powder diffraction. In: Nanocon Conference Proceedings; 2009, p. $53-60$.

[40] Watt DA. Theory of thermal diffusivity by pulse technique. Br. J. Appl. Phys. 1966; 17(2):231-40. doi:10.1088/0508-3443/17/2/311.

[41] Donaldson AB. Two-dimensional thermal attenuation of a laser pulse in a solid. J. Franklin Inst. 1972; 294(4):275-81. doi:10.1016/0016-0032(72)90025-7.

[42] Blumm J, Opfermann J. Device for determining thermal conductivity using light pulses. German patent DE 10242741A1, 2002

[43] Cowan RD. Pulse Method of Measuring Thermal Diffusivity at High Temperatures. J. Appl. Phys. 1963; 34(4):926-7. doi:10.1063/1.1729564.

[44] Woehrl N, Hirte T, Posth O, Buck V. Investigation of the coefficient of thermal expansion in nanocrystalline diamond films. Diamond Rel. Mater. 2009; 18(2-3):224-8. doi:10.1016/j.diamond.2008.10.016.

[45] Victor AC. Heat Capacity of Diamond at High Temperatures. J. Chem. Phys. 1962; 36(7):1903-11. doi:10.1063/1.1701288.

[46] Tan Z, Wang L, Shi Q. Study of heat capacity enhancement in some nanostructured materials. Pure Appl. Chem. 2009; 81(10):1871-80. doi:10.1351/PAC-CON-08-09-15. 
[47] Rupp J, Birringer R. Enhanced specific-heat-capacity (cp) measurements (150-300 K) of nanometer-sized crystalline materials. Phys. Rev. B 1987; 36(15):7888-90.

doi:10.1103/PhysRevB.36.7888.

[48] Graebner JE. Measurements of specific heat and mass density in CVD diamond. Diamond Rel. Mater. 1996; 5(11):1366-70. doi:10.1016/0925-9635(96)00550-X.

[49] May PW, Ludlow WJ, Hannaway M, Heard PJ, Smith JA, Rosser KN. Raman and conductivity studies of boron-doped microcrystalline diamond, facetted nanocrystalline diamond and cauliflower diamond films. Diamond Rel. Mater. 2008; 17(2):105-17. doi:10.1016/j.diamond.2007.11.005.

[50] Ferrari A, Robertson J. Origin of the $1150-\mathrm{cm}^{-1}$ Raman mode in nanocrystalline diamond. Phys. Rev. B 2001; 63(12):121405. doi:10.1103/PhysRevB.63.121405.

[51] Schierning G, Theissmann R, Stein N, Petermann N, Becker A, Engenhorst M et al. Role of oxygen on microstructure and thermoelectric properties of silicon nanocomposites. J. Appl. Phys. 2011; 110(11):113515. doi:10.1063/1.3658021.

[52] Field JE. The Properties of Natural and Synthetic Diamond. London, UK: Academic Press; 1992.

[53] Werheit H. Thermoelectric Properties of Boron-Rich Solids and their Possibilities of Technical Application. In: 25 ${ }^{\text {th }}$ International Conference on Thermoelectrics; 2006, p. 159163. doi:10.1109/ICT.2006.331323.

[54] Xie M, Lee CH, Wang J, Yap YK, Bruno P, Gruen DM et al. Induction annealing and subsequent quenching: Effect on the thermoelectric properties of boron-doped nanographite ensembles. Rev. Sci. Instrum. 2010; 81(4):043909. doi:10.1063/1.3378681.

[55] Aselage TL, Emin D. Boron Carbides. In: Rowe DM, editor. CRC Handbook of Thermoelectrics. Boca Raton, FL, USA: CRC Press; 1995, p. 373-386. doi:10.1201/9781420049718.ch31.

[56] Nam WH, Lim YS, Choi S, Seo W, Lee JY. High-Temperature Charge Transport and Thermoelectric Properties of a Degenerately Al-Doped ZnO Nanocomposite. J. Mater. Chem. 2012; 22(29):14633-8. doi:10.1039/c2jm31763j.

[57] Bruneaux J, Cachet H, Froment M, Messad A. Correlation between structural and electrical properties of sprayed tin oxide films with and without fluorine doping. Thin Solid Films 1991; 197(1-2):129-42. doi:10.1016/0040-6090(91)90226-N.

[58] Seto JYW. The electrical properties of polycrystalline silicon films. J. Appl. Phys. 1975; 46(12):5247-54. doi:10.1063/1.321593.

[59] Kinemuchi Y, Nakano H, Mikami M, Kobayashi K, Watari K, Hotta Y. Enhanced BoundaryScattering of Electrons and Phonons in Nanograined Zinc Oxide. J. Appl. Phys. 2010; 108(5):053721. doi:10.1063/1.3475650.

[60] Mott NF, Davis EA. Electronic processes in non-crystalline materials. 2nd ed. Oxford, UK: Clarendon/Oxford University Press; 1979.

[61] Jonker GH. The Application of combined Conductivity and Seebeck-Effect plots for the Analysis of Semiconductor Properties. Philips Res. Repts. 1968; 23:131-8.

[62] Ohtaki M, Tsubota T, Eguchi K, Arai H. High-Temperature Thermoelectric Properties of (Zn1_xAlx)O. J. Appl. Phys. 1996; 79(3):1816-8. doi:10.1063/1.360976. 
[63] Zhu Q, Hopper EM, Ingram BJ, Mason TO. Combined Jonker and Ioffe Analysis of Oxide Conductors and Semiconductors. J. Am. Ceram. Soc. 2011; 94(1):187-93.

doi:10.1111/j.1551-2916.2010.04047.x.

[64] Ioffe AF. Halbleiter-Thermoelemente. Berlin, Germany: Akademie-Verlag; 1957.

[65] Su M, Elsbernd CE, Mason TO. Jonker "Pear" Analysis of Oxide Superconductors. J. Am. Ceram. Soc. 1990; 73(2):415-9. doi:10.1111/j.1151-2916.1990.tb06527.x.

[66] Graebner JE, Jin S, Herb JA, Gardinier CF. Local thermal conductivity in chemical-vapordeposited diamond. J. Appl. Phys. 1994; 76(3):1552-6. doi:10.1063/1.357733.

[67] Wörner E, Wild C, Müller-Sebert W, Locher R, Koidl P. Thermal conductivity of CVD diamond films: high-precision, temperature-resolved measurements. Diamond Rel. Mater. 1996; 5(6-8):688-92. doi:10.1016/0925-9635(95)00390-8.

[68] Tyler WW, Wilson AC. Thermal Conductivity, Electrical Resistivity, and Thermoelectric Power of Graphite. Phys. Rev. 1953; 89(4):870-5. doi:10.1103/PhysRev.89.870.

[69] Gruen DM, Bruno P, Xie M. Configurational, electronic entropies and the thermoelectric properties of nanocarbon ensembles. Appl. Phys. Lett. 2008; 92(14):143118. doi:10.1063/1.2909150.

[70] Fellinger T, Su DS, Engenhorst M, Gautam D, Schlög1 R, Antonietti M. Thermolytic synthesis of graphitic boron carbon nitride from an ionic liquid precursor: mechanism, structure analysis and electronic properties. J. Mater. Chem. 2012; 22(45):23996-4005. doi:10.1039/c2jm34486f.

[71] Anthony TR, Banholzer WF, Fleischer JF, Wei L, Kuo PK, Thomas RL et al. Thermal diffusivity of isotopically enriched ${ }^{12} \mathrm{C}$ diamond. Phys. Rev. B 1990; 42(2):1104-11. doi:10.1103/PhysRevB.42.1104.

[72] Olson JR, Pohl RO, Vandersande JW, Zoltan A, Anthony TR, Banholzer WF. Thermal conductivity of diamond between 170 and $1200 \mathrm{~K}$ and the isotope effect. Phys. Rev. B 1993; 47(22):14850-6. doi:10.1103/PhysRevB.47.14850. 


\section{Supplementary Data}

Thermoelectric Transport Properties of Boron-doped Nanocrystalline Diamond Foils

Markus Engenhorst ${ }^{a}{ }^{*}$, Jonas Fecher ${ }^{b}$, Christian Notthoff ${ }^{a}$, Gabi Schierning ${ }^{a}$, Roland Schmechel ${ }^{a}$, Stefan M. Rosiwal ${ }^{b}$

${ }^{a}$ Faculty of Engineering and Center for Nanointegration Duisburg-Essen (CENIDE), University of Duisburg-Essen, Bismarckstraße 81, 47057 Duisburg, Germany

${ }^{b}$ Chair of Metals Science and Technology (WTM), University of Erlangen-Nuernberg, Martensstraße 5, 91058 Erlangen, Germany

(a)

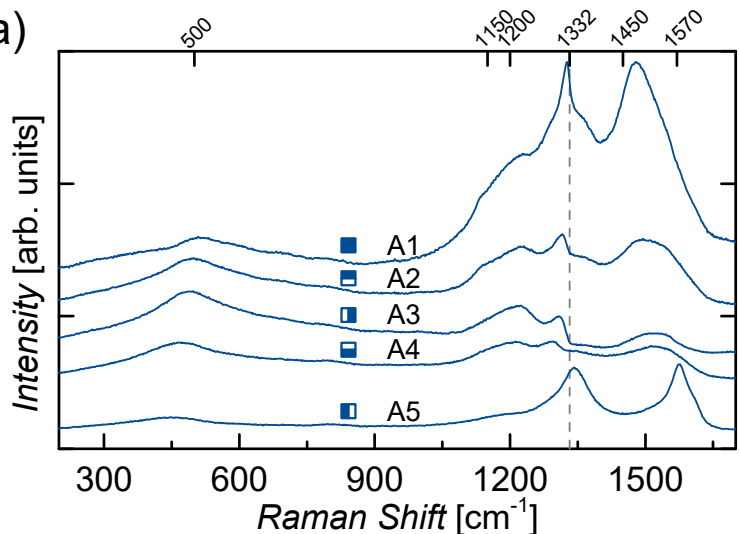

(b)

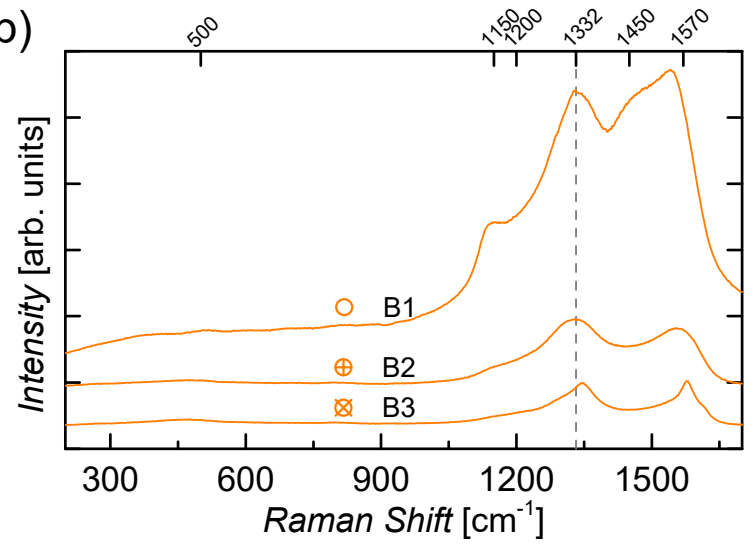

Fig. S1 - Raman spectra of (a) foils from reactor $A$ and (b) foils from reactor $B$. The spectra were acquired using a Renishaw inVia microscope with an excitation wavelength of $532 \mathrm{~nm}$.
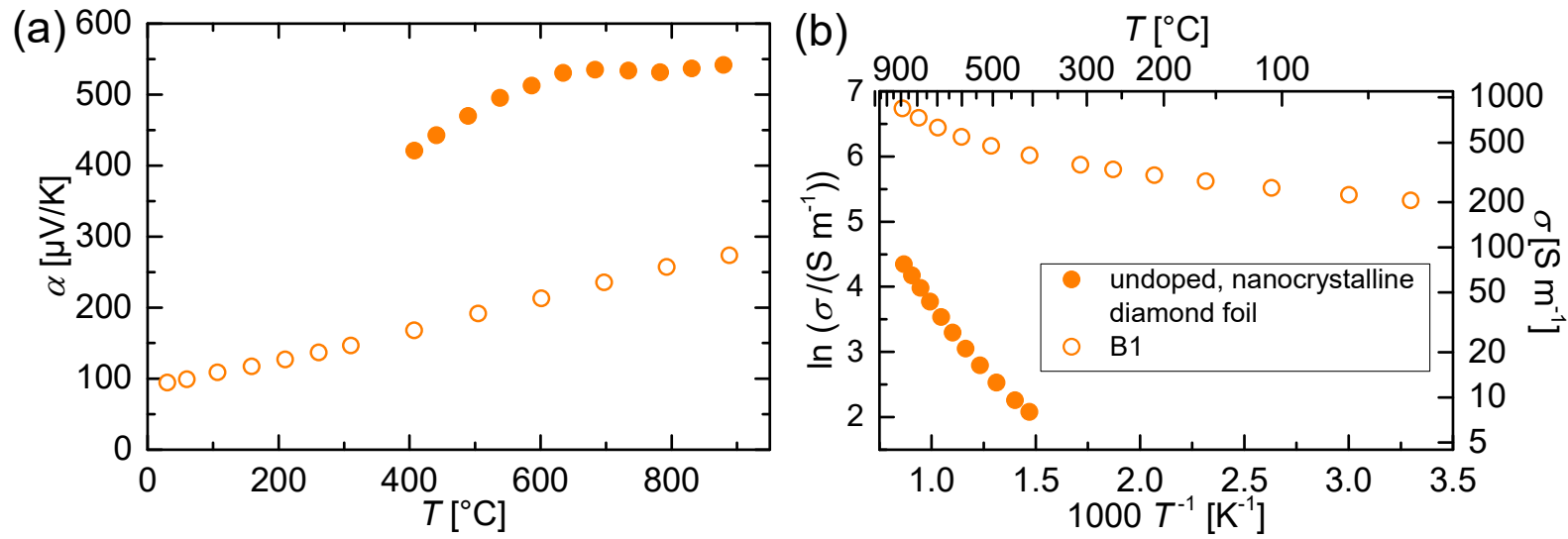

Fig. S2 - (a) Seebeck coefficient and (b) electrical conductivity of an undoped, nanocrystalline foil. Values of foil $B 1$ are given as a comparison. 


\section{Detailed discussion of X-ray diffractograms and their Rietveld refinement}

X-ray diffractograms of select foils are given in Fig. 3. Rietveld refinements with four diamond phases and the knowledge about the highly anisotropic, columnar microstructure [1] allow for the following interpretation.

The primary (111) peak and the (311) peak are greatly diminished for all foils, whereas the (220) planes produce a comparatively narrow and intense reflex. This is the most obvious effect of the strong texturing, and we suppose that the columnar grains are preferentially (220)-orientated. Another phase in the refinement is attributed to small, polycrystalline grains with random orientation which may be distributed evenly between the crystallites with preferential orientation. Compared to the latter phase, the polycrystalline phase contributes more to the broader (111) and (311) peaks. The remaining two phases merely account for the broad wings at the base of the diamond reflexes (e.g., the left shoulder of the (111) peak at $41.4^{\circ}$ ) and other low intensity peaks (e.g., at $66.9^{\circ}$ ). These wings and small peaks may originate from the nucleation layer at the initiation of growth and from intergrain material. For example, the left shoulder of the (111) peak is also observed in undoped nanocrystalline diamond (not shown). Signs of a segregation of crystalline boron or $\mathrm{B}_{\mathrm{x}} \mathrm{C}_{\mathrm{y}}$ compounds and a potential exchange of carbon and silicon between template and foil (forming $\mathrm{SiC}$ ) were not observed by means of XRD.

The strongest texturing is observed for foil B1 with the least intense (111) and (311) peaks. Foils B3 and A5 are also highly textured. Foil A3 is found to be the least textured from its comparatively intense (111) peak. During growth, the preferential orientation of its columns seems to diminish and consequently, in top-view SEM, a mixture of triangular $\{111\}$ and square $\{100\}$ facets is observed (see Fig. 2(b)), which is in agreement with the literature.[2,3] Additionally, as assessed from SEM, the in-plane extension of its columns appears to become comparatively wide with increasing deposition time.

According to the Rietveld refinement, the preferentially orientated crystallites possess average diameters of $42 \mathrm{~nm}$ (A3), $45 \mathrm{~nm}$ (A5, for which a second strongly textured phase with a diameter of $29 \mathrm{~nm}$ is observed), $66 \mathrm{~nm}$ (B1) and $40 \mathrm{~nm}$ (B3). Those values rather represent the spatial extension along the length of the columns, which explains why the values for the latter three foils are consistently larger than the values from top-view SEM. In the case of the most textured foil B1, the crystallite length from XRD is a factor of 5 larger than the in-plane diameter from SEM. Foils deposited in reactor $B$ exhibit stronger texturing, partly due to their larger thickness. A higher methane fraction during manufacturing results in shorter columns (B3) due to a higher rate of secondary nucleation than in foil B1.

In the case of foil A3, the preferentially orientated grains do not exhibit a much larger diameter than in the other foils as could be expected from the micrographs (see Fig. 2(b)). It is very probable that the apparently large grains are not single crystalline, but contain a lot of defects. Primarily, we suppose a high density of grain boundaries with virtually no width, such as twins, which cannot be easily observed in SEM, but are inherently detected in XRD. Such grain boundaries without $\mathrm{sp}^{2}$ carbon and covalent bonds probably do not nearly hinder the transport of charge carriers and phonons as much as the grain boundaries clearly visible in SEM, and that is the reason why the diameter obtained from SEM is used in the discussion. 
The crystallite size of the polycrystalline phase varies only slightly from 7 to $12 \mathrm{~nm}$ in all foils, with a relatively large uncertainty due to the strong overlap with the peaks of the textured phase.

\section{References}

[1] Graebner JE, Jin S, Kammlott GW, Herb JA, Gardinier CF. Large anisotropic thermal conductivity in synthetic diamond films. Nature 1992;359(6394):401-3.

http://dx.doi.org/10.1038/359401a0.

[2] Plano LSG. Growth of CVD Diamond for Electronic Applications. In: Pan LS, Kania, DR, editors. Diamond: electronic properties and applications. Boston, MA, USA: Kluwer; 1995. p. 61-138. http://dx.doi.org/10.1007/978-1-4615-2257-7 3.

[3] Ushizawa K, Watanabe K, Ando T, Sakaguchi I, Nishitani-Gamo M, Sato Y et al. Boron concentration dependence of Raman spectra on $\{100\}$ and $\{111\}$ facets of B-doped CVD diamond. Diamond Rel Mater 1998;7(11-12):1719-22. http://dx.doi.org/10.1016/S09259635(98)00296-9. 